\title{
Analysis on Life Education for Adolescents
}

\author{
Liyan Zhao* \\ Chengdu College of Arts and Sciences, Chengdu 610401, Sichuan Province, China \\ *Corresponding author: Liyan Zhao, zeenaly@qq.com
}

\begin{abstract}
With the increasing number of suicides among adolescents year by year along with a younger and rising trend, life education has caused widespread concern in the whole society. At present, there are some problems with the life education for young people in China, and the life education system suitable for China's national conditions needs to be further improved. The analysis of the current situation of the life education for adolescents would bring about important enlightenment for the establishment of the life education system. It is necessary to strengthen the education of life values among young people, use experiences and the home-school cooperation to help young people improve their life consciousness, learn to respect life, fear life, cherish life, as well as promote their healthy development.
\end{abstract}

Keywords: Life education; Life consciousness; Life values; Adolescents

Publication date: August 2021; Online publication: August 30, 2021

\section{Introduction}

In recent years, it has been a common scenario where adolescents neglect and maim their lives; this includes suicide, self-mutilation, and murdering others. In particular, suicide among adolescents is increasing year by year. This phenomenon has attracted great attention from educators and people from all walks of life. At the same time, it has also triggered people's contemplation on life education among adolescents. At present, there is a sense of urgency for life education among adolescents. In fact, as early as May 2010, life education has been included into the outline of China's National Plan for Medium and Long-Term Education Reform and Development (2010-2020). It has become one of the six major educations, parallel to physical education, labor education, safety education, national defense education, and sustainable development education. This outline has issued a license for life education from the national level. In the following ten years, although there have been many studies on the concept of life education and curriculum planning, there are various shortcomings in the existing studies to different degrees, such as the lack of pertinence, systematicness, and effectiveness. At the same time, there have been many analyses at the concept level, but the research on curriculum teaching, policy formulation, methods, and approaches are relatively weak. In particular, the curriculum design of life education suitable for national conditions is very lacking. There is no content system suitable for its own development. Therefore, at present, it is necessary to conduct more research on adolescents, enrich the content of life education, and build an adolescent life education content system in line with China's local characteristics.

\section{Necessity of developing life and health education for adolescents}

\subsection{Improvement of the overall national quality}

The quality of adolescents determines the future quality of the nation, in which life education is an important part of quality education. If adolescents do not recognize the concept of life and life consciousness, they are likely to fail in reflecting the real value and pursuit in life, having no concern for life, abandoning 
themselves, having negative emotions, complaining about the society, and eventually, they would go down the road of breaking laws and committing crimes. Adolescents are in the phase of rebellion, thus requiring that education needs to strictly begin from life education in order to cultivate adolescents' life consciousness and life concept so that they fear, respect, and cherish life. In that way, they would be able to establish correct values, develop correct value orientation, and make life more meaningful along with their growth.

\subsection{Development of the social environment}

With the development of the world economic integration and the diversification of cultural ideas, foreign advanced science, technology, and cultural ideas have been entering China; poor ideas and ethos are gradually destroying the foundation of China's social thought and impacting people's spiritual world. In recent years, several adolescents have suffered from campus bullying, accidental injuries, and other unacceptable behaviors due to the erosion of these ideas. This situation is very unfavorable to the growth and development of adolescents. In view of these negative phenomena, it is necessary to strengthen education while taking life and health education as the basis; beginning from youth education, help them to establish life consciousness, allow the correct values to enrich their spiritual world, and promote their healthy growth and development.

\subsection{New concept of modern education}

It has been found that traditional teaching activities lack education and guidance from the aspects of personality, psychology, and ethics. This is particularly unfavorable to the growth of children and adolescents. Hence, there has been reflections on the defects in teaching, reformation and change of the previous teaching ideas, as well as new ideas for a modern education. This concept advocates using life education and psychological education activities for children and adolescents as the basis, cultivating good behavior habits and ideology, guiding them to pay attention to and respect life, as well as promoting an allrounded and healthy growth.

\section{Problems in life education for adolescents}

\subsection{Adolescents lack life consciousness, and their life values are prone to deviation}

The social and economic development in China is growing day by day. Along with that, social thoughts are sweeping in. People are under tremendous pressure and have minimal leisure time in this fast-paced life. This has a great impact on adolescents in regard to their life values, and it is easier for them to feel confused about their own future and life ${ }^{[3]}$. In the era of modernization, relationships between people in the society are becoming more and more subtle. In pursuit of material wealth and the improvement of the quality of life, some people would do things which hurt others for the sake of power, and even pay heavy prices for their own interests. These behaviors are extremely shocking to adolescents who lack life experience and social experience. It is beneficial for them to have some doubts about the value and significance of life. Adolescents, who are at puberty, have a strong curiosity and thirst for knowledge about external things. They would understand the major and minor events in the society in various ways, thus growing a utilitarian heart. In order to achieve their own goals, they will resort to all means, thus completely lose the pursuit of the humanistic spirit while their lofty ideals are distorted, making them more and more indifferent; their psychology will change in varying degrees and their consciousness toward life will gradually fade. 


\subsection{Adolescents lack the sense of the meaning of life, and they have poor ability to resist setbacks due to the lack of family education}

Family education has an important influence on adolescents' life education. Each member in a family has different personalities, understandings, and views on things. Nowadays, the rapid development of the society has raised the living standards. Along with that, people's hearts are changing subtly, and their thoughts are expanding. The behaviors and thoughts of parents affect their children all the time. A child's character, way of dealing with the world, and attitude towards things are closely related to his or her parents. In modern society, family structures are relatively scattered; there are more and more single parent families, which brings varying degrees of harm to children. For example, adolescents who are living in indifferent families lack the attention from their parents and the quality of parent-child relationship is poor. Their perception of happiness will be relatively poor and they would often think that life is meaningless. However, adolescents living in excessively doting families are more self-centered, and their ability to resist setbacks is poor. Once they encounter setbacks, they are unable to face them properly; instead, they use extreme means to solve their problems.

\section{Strategies in adolescents' life education}

\subsection{Strengthening the education of life values among adolescents}

Life values education is an important part of life education. Life values refer to the fundamental views of each individual in judging and creating life values. Guiding adolescents to establish correct life values is conducive for them to experience the significance of life in their growth. In the education of life values, the care for the healthy growth of adolescents' life should be taken as a foothold while guiding them to establish positive and healthy life values. Specifically, it mainly includes two aspects. The first, paying attention to personality education and cultivate healthy psychology among adolescents as sound personality is the basis for forming positive life values. If their personalities are not perfect, it will be difficult to form correct life values. The other, carrying out humanistic care and humanistic education for adolescents to improve their moral quality. Humanistic care as well as the respect for their individual needs and personality differences would help to stimulate their initiative, enthusiasm, and creativity in addition to promote the formation of positive life values ${ }^{[4]}$.

\subsection{Allowing adolescents to improve their life consciousness through experience}

Experience is an important method to strengthen the education of life care and improve adolescents' life consciousness. Families, schools, and the society should cooperate closely, actively create a variety of practical activities, and guide adolescents to understand the value of life in their participation and experience. At present, several safety education experience pavilions have been created all over the country, such as safety education experience pavilions. This kind of teaching method is more interesting than the traditional classroom teaching. In the safety education experience hall, multiple plates can be set, such as home safety plate, fire safety plate, construction safety plate, traffic safety plate, and so on. Through this design, the knowledge of safety protection can be taught from all aspects and at multiple levels so as to improve adolescents' ability to prevent and respond to various safety events or natural disasters.

\subsection{Home-school collaboration as an important way to strengthen adolescents' life education}

Home school collaboration is an important way to implement life education. Many issues in the process of life education often affect the effect of education because of the lack of consensus between families and schools as well as the inability to form an educational joint force. Therefore, families and schools need to reach a consensus on life education; that is, schools and families need to uphold the common concept of 
life education ${ }^{[5]}$. Home-school collaboration requires the joint efforts of parents and schools to carry out educational activities to promote the healthy growth of adolescents. Under the schools' education model, the first pilot is to involve parents and create a new pattern of teaching or educating. Under this model, schools can involve parents in practical activities and teaching. However, teachers should master their communication skills. On the one hand, they should improve their own communication methods. On the other hand, they should understand the ideological views of the parents, choose appropriate communication methods, and build a bridge for the healthy growth of adolescents with joint efforts. In order to improve life consciousness and promote good mental health development among adolescents, schools and parents need to go hand in hand and actively establish diversified practical activities.

\section{Conclusion}

Adolescents' life education is not only related to their personal growth, but also the social progress and national development. The exploration of life education for adolescents is a long-term and arduous task, which requires joint efforts from families, schools, and the society. In the new era, parents and educators should take life education as the core of education and infiltrate life education in all aspects of daily life or teaching. It should be noted that in the implementation of life education, it is vital to understand the psychological characteristics and needs of these adolescents, continuously optimize the guidance of life education according to modern educational concepts, as well as make full use of the home-school network communication platform in order to further promote a home-school collaborative life education.

\section{Funding}

This research was supported by the School-Level Scientific Research Project of Chengdu College of Arts and Sciences in 2021 "Research on the Present Situation, Problems and Countermeasures of Adolescents' Life Values Education” (No. WLYB2021062).

\section{Disclosure statement}

The author declares that there is no conflict of interest.

\section{References}

[1] Cohen P, Cohen J, 2013, Life Values and Adolescent Mental Health, Psychology Press.

[2] Svetkova IV, 2006, Health as a Life Value of Adolescents. Russian Education and Society, 48(8): 31 9.

[3] Chen M, 2006, Problem Analysis and Educational Guidance of Contemporary Youth's Life Values. Northeast Normal University, Changchun, 2.

[4] Chen Q, Tan J, 2021, Youth Life Education from the Perspective of Home School Cooperation. Educational Literature Collection, (3): 8-10.

[5] Li F, 2012, Some Thoughts on Strengthening the Education of Adolescents' Life Values. Journal of Tianjin Academy of Educational Sciences, (6): 54-7. 